\title{
Chronic Lymphocytic Leukemia in the SARS-CoV-2 Pandemic
}

\author{
Abril Adriana Arellano-Llamas ${ }^{1} \cdot$ Jorge Vela-Ojeda $^{2} \cdot$ Alvaro Hernandez-Caballero $^{2}$ \\ Accepted: 22 September 2021 / Published online: 21 January 2022 \\ (c) The Author(s), under exclusive licence to Springer Science+Business Media, LLC, part of Springer Nature 2022
}

\begin{abstract}
Purpose of Review Chronic lymphocytic leukemia (CLL) is the most frequent lymphoproliferative disease in the elderly of the western world. Immune defective responses and treatment can worsen the immune system's competence of CLL patients. Consequently, they may present a higher incidence of recurrent severe infections, second malignancies, and reduced efficacy of vaccines. The outbreak of COVID-19 is an ongoing pandemic, and patients with comorbidities experience more severe forms of the disease. Hematological malignancies are associated with higher case fatality rates (CFRs) than other cancers. Knowledge about COVID-19 incidence, clinical course, and immune response to the infection and vaccination in CLL may contribute to design strategies that improve the outcomes of patients in the future.

Recent Findings The prevalence of SARS-CoV-2 positivity in CLL is not significantly higher than seen in the general population. CFRs for CLL patients are 16.5-fold more elevated than the median reported worldwide and even higher in older patients, those who require hospitalization have significant comorbidities or need oxygen therapy. CLL status decreases the anti-SARS-CoV-2 positivity after infection or vaccination by around $40 \%$, and the spike-specific antibody titers are 74 -fold lower than healthy age-matched controls. The response rate to COVID-19 vaccines is even worse in patients with active CLL-directed therapies like BTKi, BCL-2 antagonists, or anti-CD20 monoclonal antibodies.

Summary CLL patients are at a greater risk of death from COVID-19. Inherent immunosuppression of CLL and immune deficiencies caused by treatment significantly decrease the ability to produce natural or vaccine-induced anti-SARS-CoV-2 immune responses.
\end{abstract}

Keywords SARS-CoV-2 $\cdot$ COVID-19 $\cdot$ CLL $\cdot$ Chronic lymphocytic leukemia $\cdot$ Antibody $\cdot$ Vaccine $\cdot$ BTK inhibitors

\section{Introduction}

Severe acute respiratory syndrome coronavirus-2 (SARSCoV-2) and its related disease, coronavirus disease of 2019 (COVID-19) severely affected worldwide since first detected in December 2019 in Wuhan, China [1]. COVID-19 has a heterogeneous course, ranging from asymptomatic infection or mild symptoms to a very aggressive disease with acute

This article is part of the Topical Collection on Leukemia

Alvaro Hernandez-Caballero

alvheca@gmail.com

1 Department of Endocrinology, UMAE Hospital General Centro Medico La Raza, Instituto Mexicano del Seguro Social, Seris y Zaachila, La Raza, Azcapotzalco, 02900 Mexico City, Mexico

2 Department of Hematology, UMAE Hospital de Especialidades Centro Medico La Raza, Instituto Mexicano del Seguro Social, Mexico City, Mexico respiratory failure and multiorgan failure [2]. In the general population, the estimate of infection fatality rate is $0.68 \%$, with an exponential increase with age up to $5.6 \%$ for those 65 years and older [3]. Many patients with severe forms of COVID-19 have evidence of comorbidities such as obesity, cardiovascular disease, liver disease, kidney disease, immunosuppression, or cancer [4]. In general, patients with hematological malignancies have more severe disease and a higher case fatality rate than other cancers [5]. However, patients with no active cancer (watch and wait surveillance or complete remission) presented better outcomes [6].

Chronic lymphocytic leukemia (CLL) is the most common form of leukemia in adults in countries with a predominantly Caucasian population [7]. This condition clusters many of the risk factors associated with severe forms of COVID-19, primarily affects the elderly, with the majority of patients being $>65$ years of age at diagnosis [8], is associated with impaired immune function [9] that results in 
inadequate response to vaccination [10], and is treated with agents that modulate the immune system [11].

\section{COVID-19 Incidence in CLL Patients}

From the beginning of the pandemic, a relevant question was if some conditions could increase the risk of SARSCoV-2 infection or more severe forms of COVID-19. CLL patients were of particular interest because of the intrinsic immunosuppression caused by the disease and the need for continuous treatment to obtain leukemia control.

In August 2020, Cuneo et al. reported a survey based on 9930 patients with CLL managed during the COVID-19 pandemic from 33 centers, accounting for approximately one-third of all patients in Italy. The prevalence of COVID19 positivity in CLL was estimated at $0.5 \%$, not significantly higher than seen in the general population. Other interesting findings were that patients experienced delays in treatment initiation or the administration of planned courses, restraints in the use of blood products, and the need for postpose restaging after treatment [12•].

\section{Outcomes to COVID-19 in Patients with CLL}

As of August 2021, the SARS-CoV-2 pandemic has resulted in 215 million infections worldwide and more than 4 million deaths from COVID-19. The median global case fatality rate (CFR) is estimated to be $1.7 \%$, ranging from 18.8 to $0.1 \%$ [13]. Symptomatic patients of COVID-19 belong mostly to the 40-70 years age group, and the most common symptoms are fever (83.3\% [95\% CI 78.4-87.7]), cough (60.3\% [54.2-66.3]), and fatigue (38.0\% [29.8-46.5]). Some patients may also present myalgias, breathlessness, abdominal pain, vomiting, and diarrhea [14].

Two extensive cohort studies have characterized the clinical course of CLL patients diagnosed with COVID-19. In July 2020, the European Research Initiative on CLL (ERIC) and the CLL Campus published a retrospective international multicenter study based on a survey completed by 121 investigators from 118 sites. From 221 cases with suspected COVID-19, one-hundred and ninety (92.2\%) were positive for molecular tests. Incidence of COVID-19 reported among 15,083 cases was $1.06 \%$, and $0.9 \%$ of patients required hospitalization $[15 \bullet \bullet]$. Two months later, another multicenter, international cohort study was reported with data from 198 patients. Fifty percent of cases were diagnosed in the USA and $48 \%$ in Europe or the UK [16••].

With the primary goal of reporting the CFR of a large group of patients with CLL and COVID-19 and analyzing mortality trends over time, a study with 374 patients from 45 centers in the USA and Europe was published in July
2021. The analysis of all patients included 374 patients with a median follow-up of 38 days (range 1-364 days). The CFR reported was $28 \%$, with significant differences between the patients who required hospitalization (36\%) and those treated at home (4.3\%). In the univariate analysis, age $>75$ years and cumulative illness rating scale-geriatric (CIRS) $>6$ were independent predictors of poor survival. When comparing two cohorts, investigators found that patients treated from February to April 2020 required hospital (85\% vs. $55 \%)$ and ICU admission (32\% vs. $15 \%)$ more frequently with a higher CFR when compared with patients treated from May 2020 to February 2021. The CFR for patients requiring hospitalization and oxygen therapy was also higher in the patients treated after May 2020, and the proportion of BTK inhibitor (BTKi) hold or discontinuation was reduced over time $[17 \bullet \bullet]$.

Data shown in Table 1 compares age, comorbidities, CLL treatment status at the time of COVID-19 diagnosis, and admission requirements of the three cohorts previously mentioned. The age at COVID-19 diagnosis was very uniform, consistent with the typical prevalence of CLL in the elderly. The frequency of comorbidities was similar between Scarfo and Mato reports, with a greater proportion of hypogammaglobulinemia in the ERIC experience. Interestingly, the proportion of patients that received CLL treatment previously or were untreated at the time of COVID-19 diagnosis was the same in the Scarfo and Mato experience, in contrast with the Roeker cohort that reported a more significant proportion of untreated patients. The CLL treatment used more frequently was BTKi in close to one-third of the patients; the second preferred regimen was venetoclax, with less than $10 \%$ in all the cohorts.

Presenting symptoms in patients with CLL diagnosed with COVID-19 are shown in Table 2. All symptoms of COVID-19 were more frequent in the study of Mato et al., except for hyperthermia, which was present in nearly the same proportion in two cohorts of CLL patients. In order to compare the clinical course of CLL patients with the general population, Table 2 includes data of a different group of adults with a median age of 77.5 years, very similar to CLL patients [18]. The only symptom that was noticeably different was the fever, being more prevalent in leukemia patients.

\section{Impact of CLL Diagnosis in the Immune Response to SARS-CoV-2 Vaccination}

B cells produce antibodies in response to viral infection or vaccination. Antibodies constitute the first line of defense against viral diseases. Neutralizing antibodies produced by exposure to the virus or vaccination protect against new infections blocking virus entry into host cells. Their measurement in plasma is a valuable tool to determine 
Table 1 Comparison of patient baseline characteristics

\begin{tabular}{|c|c|c|c|}
\hline \multirow[t]{2}{*}{$n$} & $\begin{array}{l}\text { Scarfo et al. July } \\
2020[15 \bullet \bullet]\end{array}$ & $\begin{array}{l}\text { Mato et al. Septem- } \\
\text { ber } 2020[16 \bullet \bullet]\end{array}$ & $\begin{array}{l}\text { Roeker et al } \\
\text { July } 2021 \\
{[17 \bullet \bullet]}\end{array}$ \\
\hline & 190 & 198 & 374 \\
\hline Median age at COVID-19 diagnosis (range) & $72(48-94)$ & $70.5(38-98)$ & $68(29-98)$ \\
\hline \multicolumn{4}{|l|}{ Comorbidities } \\
\hline Hypertension & $54 \%$ & $51 \%$ & \\
\hline Diabetes mellitus & $24 \%$ & $20 \%$ & \\
\hline COPD & $6 \%$ & $11 \%$ & \\
\hline Cardiovascular & $29 \%$ & $33 \%$ & \\
\hline Hypogammaglobulinemia & $57.8 \%$ & $44 \%$ & \\
\hline Other & $26 \%$ & $33 \%$ & \\
\hline \multicolumn{4}{|l|}{ CLL treatment history } \\
\hline Previously untreated & $39 \%$ & $39 \%$ & $45 \%$ \\
\hline Prior therapy & $61 \%$ & $61 \%$ & $55 \%$ \\
\hline CLL therapy at COVID-19 diagnosis & $34 \%$ & $45 \%$ & $38 \%$ \\
\hline BTK inhibitor & $23.2 \%$ & $30.8 \%$ & $26 \%$ \\
\hline Venetoclax based & $4.7 \%$ & $7 \%$ & $8 \%$ \\
\hline PI3K inhibitor-based & $1.6 \%$ & $1 \%$ & \\
\hline Bendamustine + rituximab & $1 \%$ & $0.5 \%$ & \\
\hline Other & $2.1 \%$ & $6 \%$ & \\
\hline \multicolumn{4}{|l|}{ COVID-19 management } \\
\hline Hospitalization & $68.4 \%$ & $90 \%$ & $75 \%$ \\
\hline ICU admission & $20.5 \%$ & $35 \%$ & $27 \%$ \\
\hline
\end{tabular}

Table 2 Clinical presentation of CLL patients with COVID-19

\begin{tabular}{llll}
\hline & $\begin{array}{l}\text { CLL cohort } \\
\text { Scarfó et al. } \\
\text { July 2020 } \\
{[15 \bullet \bullet]}\end{array}$ & $\begin{array}{l}\text { CLL cohort } \\
\text { Mato et al. } \\
\text { September 2020 } \\
{[16 \bullet \bullet]}\end{array}$ & $\begin{array}{l}\text { Elderly popu- } \\
\text { lation } \\
\text { Kerr et al. } \\
\text { November } \\
2020[18]\end{array}$ \\
\hline Fever & $87 \%$ & $88 \%$ & $57 \%$ \\
Cough & $49 \%$ & $85 \%$ & $51.3 \%$ \\
$\begin{array}{l}\text { Dyspnea } \\
\text { Myalgias/ }\end{array}$ & $48 \%$ & $74 \%$ & $53 \%$ \\
arthralgias & $15 \%$ & $36 \%$ & \\
$\begin{array}{l}\text { Nausea and } \\
\text { vomiting }\end{array}$ & $3 \%$ & $14 \%$ & $13.9 \%$ \\
$\begin{array}{l}\text { Diarrhea } \\
\text { Fatigue }\end{array}$ & $12 \%$ & $29 \%$ & $16.5 \%$ \\
Sore throat & $4 \%$ & $72 \%$ & $27.8 \%$ \\
\hline
\end{tabular}

response to infections and efficacy of vaccines [19]. IgG anti-SARS-CoV antibodies are detected in $95.3 \%$ of COVID-19 patients 5 weeks after symptom onset. A delay in IgG development is associated with a higher incidence of severe or critical disease, and the IgG levels are higher in older patients and those with more severe forms of the disease. IgG levels against spike protein (S) or the receptor-binding domain (RBD) are particularly important in viral clearance and COVID-19 recovery [20].

Serology testing in twenty-one CLL patients at a median of 55 days after diagnosis found that only $67 \%$ of patients had detectable levels of antiSARS-CoV-2 IgG antibodies. Hypogammaglobulinemia was negatively associated with antibody response, and $\mathrm{IgG}$ production was more frequent in CLL patients that recovered from severe COVID-19 [21].

The evidence of the ability to neutralize the SARS-CoV2 by human antibodies resulted in the development of multiple effective and safe COVID-19 vaccines at an unprecedented speed to achieve protective immunity and eradicate this pandemic. The approved vaccines have shown outstanding efficacy inducing antibody levels of similar or higher magnitude as those observed after exposure to the virus. Fully vaccinated people gain almost complete protection against hospitalization and severe disease [22].

Intrinsic immune impairment in CLL patients and CLLdirected therapy may impact the efficacy of vaccines. For example, a paper by Pleyer et al. reported a $4 \%$ response rate to the recombinant hepatitis $\mathrm{B}$ vaccine in patients treated with BTKi, in contrast to a $28 \%$ response rate in treatmentnaïve patients. Response to the recombinant herpes zoster vaccine also was reduced by BTKi therapy [23•].

Roeker et al. analyzed the serum levels of anti-SARSCoV-2 S1/S2 antibodies in 44 patients with CLL who received 
two doses of mRNA vaccine BNT162b2 (BioNTech \& Pfizer) or mRNA-1273 (Moderna \& NIH, EE. UU.). Forty-one percent of patients were on treatment at the time of the vaccination, $32 \%$ with BTKi, $32 \%$ with anti-CD20 mAB, and $16 \%$ with venetoclax. CLL treatment was not held or modified before immunization. Half of the patients were positive for anti-SARS-CoV-2 S1/S2 antibodies. Antibody positivity was strongly associated with untreated CLL and age $<70$ years [24•].

In another study, anti-SARS-CoV-2 $\mathrm{S}$ antibodies were measured from 2 to 3 weeks after the second dose of the BNT162b2 mRNA COVID-19 vaccine in 167 patients with CLL/SLL and 52 healthy control subjects. Almost one-third of CLL patients were treatment naïve, $44.9 \%$ were on CLLdirected therapy, $14.4 \%$ were on remission, and $6.0 \%$ were on disease relapse after being previously treated. Antibody response to the vaccine was present in only $39.5 \%$ of patients with CLL, in contrast to $100 \%$ in age- and sex-matched control subjects. CLL patients with a serologic response to vaccination also showed lower antibody titers than their healthy counterparts. Age $<65$ years, female gender, mutated IGHV status, $\beta 2$-microglobulin $\leq 3.5 \mathrm{mg} / \mathrm{L}$, early disease stage, lack of active treatment, and higher serum immunoglobulin levels were all associated with higher antibody responses. CLL treatment at the time of vaccination severely impaired antibody production. The response rate to the vaccine was $16 \%$ in patients receiving BTKi, $13.6 \%$ in patients treated with venetoclax \pm anti-CD20 antibodies, and absent in patients treated with anti-CD20 antibodies within the last 12 months before vaccination. Even treatment-naive patients have reduced responses and lower antibody titers than healthy individuals, presumably caused by qualitative and quantitative immune defects intrinsic to the leukemia diagnosis [25••].

Finally, a study conducted in the UK enrolled 299 CLL patients and 93 age-matched healthy donors that received either the PfizerBioNTech mRNA vaccine $(51.5 \%)$ or the AstraZeneca/Oxford ChAdOx1 adenovirus vaccine (48.5\%). Samples from CLL patients had a 2.8-fold lower response rate and 104-fold lower antibody titers than age-matched healthy donors following first vaccine dose. Spike-specific antibody production was particularly impaired in patients on BTKi therapy. After the second vaccination, spike-specific antibody responses were identified in $75 \%$ of samples from the patient group, but the titer was 74-fold lower than healthy age-matched controls. BTKi treatment was also a strong and independent predictor of negative antibody response after the second vaccine $[26 \bullet \bullet]$.

\section{Conclusion}

Patients with CLL face an unprecedented adverse situation. In addition to the adverse events caused by cancer, they are at a greater risk of dying from complications related to COVID-19. According to the World Health Organization, CLL patients belong to the higher priorities on using vaccines against COVID-19, even when the efficacy of immunization in this population is very low. Vaccinated patients with CLL should continue to adhere to masking and social distancing recommendations. Research and clinician's experience must guide decisions about cancer therapy and vaccination optimization during the SARS-CoV-2 pandemic.

Author Contribution AAAL and AHC conceived the review. AAAL searched the literature and provided relevant references. AAAL and AHC reviewed and analyzed the literature. AHC drafted the report. AAAL edited the manuscripts and JVO performed revisions. AAAL and JVO verified the accuracy of references. AHC is a consultant for Janssen, Abbvie, and Roche.

\section{Declarations}

Ethics Approval Not applicable.

Human and Animal Rights and Informed Consent This article does not contain any studies with human or animal subjects performed by any of the authors.

Conflict of Interest The authors declare no competing interests.

\section{References}

Papers of particular interest, published recently, have been highlighted as:

- Of importance

$\bullet$ Of major importance

1. Zhu N, Zhang D, Wang W, Li X, Yang B, Song J, et al. A novel coronavirus from patients with pneumonia in China, 2019. N Engl J Med. 2020;382:727-33. https://doi.org/10.1056/NEJMo a2001017.

2. Chen N, Zhou M, Dong X, Qu J, Gong F, Han Y, et al. Epidemiological and clinical characteristics of 99 cases of 2019 novel coronavirus pneumonia in Wuhan, China: a descriptive study. Lancet. 2020;395:507-13. https://doi.org/10.1016/S01406736(20)30211-7.

3. Meyerowitz-Katz G, Merone L. A systematic review and metaanalysis of published research data on COVID-19 infection fatality rates. Int J Infect Dis. 2020;101:138-48. https://doi.org/10. 1016/j.ijid.2020.09.1464.

4. Wang T, Du Z, Zhu F, Cao Z, An Y, Gao Y, et al. Comorbidities and multiorgan injuries in the treatment of COVID-19. Lancet. 2020;395:e52. https://doi.org/10.1016/S0140-6736(20)30558-4.

5. He W, Chen L, Chen L, Yuan G, Fang Y, Chen W, et al. COVID-19 in persons with haematological cancers. Leukemia. 2020;34:1637-45. https://doi.org/10.1038/s41375-020-0836-7. 
6. Martín-Moro F, Marquet J, Piris M, Michael BM, Sáez AJ, Corona $\mathrm{M}$, et al. Survival study of hospitalised patients with concurrent COVID-19 and haematological malignancies. Br J Haematol. 2020;190:e16-20. https://doi.org/10.1111/bjh.16801.

7. Al-Hamadani M, Habermann TM, Cerhan JR, Macon WR, Maurer MJ, Go RS. Non-Hodgkin lymphoma subtype distribution, geodemographic patterns, and survival in the US: A longitudinal analysis of the National Cancer Data Base from 1998 to 2011. Am J Hematol. 2015;90:790-5. https://doi.org/10.1002/ajh.24086.

8. Alrawashdh N, Sweasy J, Erstad B, McBride A, Persky DO, Abraham I. Survival trends in chronic lymphocytic leukemia across treatment eras: US SEER database analysis (1985-2017). Ann Hematol. 2021. https://doi.org/10.1007/s00277-021-04600-1 Online ahead of print.

9. Freeman JA, Crassini KR, Best OG, Forsyth CJ, Mackinlay NJ, Han P, et al. Immunoglobulin G subclass deficiency and infection risk in 150 patients with chronic lymphocytic leukemia. Leuk Lymphoma. 2013;54:99-104. https://doi.org/10.3109/10428194. 2012.706285 .

10. Whitaker JA, Parikh SA, Shanafelt TD, Kay NE, Kennedy RB, Grill DE, et al. The humoral immune response to high-dose influenza vaccine in persons with monoclonal B-cell lymphocytosis (MBL) and chronic lymphocytic leukemia (CLL). Vaccine. 2021;39:1122-30. https://doi.org/10.1016/j.vaccine.2021.01.001.

11. Solman IG, Blum LK, Burger JA, Kipps TJ, Dean JP, James $\mathrm{DF}$, et al. Impact of long-term ibrutinib treatment on circulating immune cells in previously untreated chronic lymphocytic leukemia. Leuk Res. 2021;102:106520. https://doi.org/10.1016/j.leukr es.2021.106520.

12. Cuneo A, Rigolin GM, Coscia M, Quaresmini G, Scarfò L, Mauro FR, et al. Management of chronic lymphocytic leukemia in Italy during a one year of the COVID-19 pandemic and at the start of the vaccination program. A Campus CLL report. Hematol Oncol. 2021. https://doi.org/10.1002/hon.2899. Online ahead of print. This survey analyzed the course of 9930 patients with CLL treated during the COVID-19 emergency in 33 centers across Italy. The reported prevalence of symptomatic COVID-19 cases in CLL patients was similar to the average population. COVID-19 situation in hospitals impacted on treatment routine of CLL patients.

13. Dong E, Du H, Gardner L. An interactive web-based dashboard to track COVID-19 in real time. Lancet Infect Dis. 2020;20:533-4. https://doi.org/10.1016/S1473-3099(20)30120-1.

14. Fu L, Wang B, Yuan T, Chen X, Ao Y, Fitzpatrick T, et al. Clinical characteristics of coronavirus disease 2019 (COVID-19) in China: a systematic review and meta-analysis. J Infect. 2020;80:656-65. https://doi.org/10.1016/j.jinf.2020.03.041.

15.•• Scarfò L, Chatzikonstantinou T, Rigolin GM, Quaresmini G, Motta $\mathrm{M}$, Vitale $\mathrm{C}$, et al. COVID-19 severity and mortality in patients with chronic lymphocytic leukemia: a joint study by ERIC, the European Research Initiative on CLL, and CLL Campus. Leukemia. 2020;34:2354-63. https://doi.org/10.1038/s41375-020-0959$\mathrm{x}$. This retrospective international multicenter study characterized the course of COVID-19 in patients with CLL. Severe COVID-19 was associated with age $\geq 65$ years. Hospitalization rate for severe COVID-19 was significantly lower for patients on ibrutinib treatment.

16.•• Mato AR, Roeker LE, Lamanna N, Allan JN, Leslie L, Pagel JM, et al. Outcomes of COVID-19 in patients with CLL: a multicenter international experience. Blood. 2020;136:1134-43. https://doi. org/10.1182/blood.2020006965. This study included data from 198 CLL patients diagnosed with symptomatic COVID-19 across 43 international centers. They found a high risk of death in CLL patients admitted with COVID-19. Treatment with BTKi's at COVID-19 diagnosis did not modify survival.

17.•• Roeker LE, Eyre TA, Thompson MC, Lamanna N, Coltoff A, Davids MS, et al. COVID-19 in patients with CLL: improved survival outcomes and update on management strategies. Blood. 2021:blood.2021011841. https://doi.org/10.1182/blood.20210 11841. Online ahead of print. This retrospective study from 45 centers identified a high case fatality rate in CLL patients infected with SARS-CoV-2. Older age and frailty were associated with poorer outcomes. Mortality declined over time.

18. Kerr AD, Stacpoole SR. Coronavirus in the elderly: a late lockdown UK cohort. Clin Med. 2020;20:e222-8. https://doi.org/10. 7861/clinmed.2020-0423.

19. Castro Dopico X, Ols S, Loré K, Karlsson Hedestam GB. Immunity to SARS-CoV-2 induced by infection or vaccination. J Intern Med. 2021. https://doi.org/10.1111/joim.13372. Online ahead of print.

20. Li K, Huang B, Wu M, Zhong A, Li L, Cai Y, et al. Dynamic changes in anti-SARS-CoV-2 antibodies during SARSCoV-2 infection and recovery from COVID-19. Nat Commun. 2020;11:6044. https://doi.org/10.1038/s41467-020-19943-y.

21. Roeker LE, Knorr DA, Pessin MS, Ramanathan LV, Thompson MC, Leslie LA, et al. Anti-SARS-CoV-2 antibody response in patients with chronic lymphocytic leukemia. Leukemia. 2020;34:3047-9. https://doi.org/10.1038/s41375-020-01030-2.

22. Dagan N, Barda N, Kepten E, Miron O, Perchik S, Katz MA, et al. BNT162b2 mRNA COVID-19 vaccine in a nationwide mass vaccination setting. N Engl J Med. 2021;384:1412-23. https://doi.org/ 10.1056/NEJMoa2101765.

23. Pleyer C, Ali MA, Cohen JI, Tian X, Soto S, Ahn IE, et al. Effect of Bruton tyrosine kinase inhibitor on efficacy of adjuvanted recombinant hepatitis B and zoster vaccines. Blood. 2021;137:185-9. https://doi.org/10.1182/blood.2020008758. This manuscript reported the results of two open-label, single-arm clinical trials to measure the effect of BTK inhibitors on the immune response to recombinant hepatitis $B$ and zoster vaccines. This study opened the discussion of the efficacy of other vaccines during CLL-directed therapy.

24. Roeker LE, Knorr DA, Thompson MC, Nivar M, Lebowitz S, Peters N, et al. COVID-19 vaccine efficacy in patients with chronic lymphocytic leukemia. Leukemia. 2021:1-3. https://doi. org/10.1038/s41375-021-01270-w. Online ahead of print. This is one of the first studies that reported the serologic response to COVID-19 vaccines in patients with chronic lymphocytic leukemia. Frequency of detectable anti-SARS-CoV-2 S1/S2 antibodies was low, particularly in patients receiving CLLdirected therapy.

25.• Herishanu Y, Avivi I, Aharon A, Shefer G, Levi S, Bronstein Y, et al. Efficacy of the BNT162b2 mRNA COVID-19 vaccine in patients with chronic lymphocytic leukemia. Blood. 2021;137:3165-73. https://doi.org/10.1182/blood.2021011568. This study compared the humoral immune responses to a messenger RNA COVID-19 vaccine between CLL patients and healthy controls. Efficacy was impaired by disease activity and treatment.

26.• Parry H, McIlroy G, Bruton R, Ali M, Stephens C, Damery S, et al. Antibody responses after first and second Covid-19 vaccination in patients with chronic lymphocytic leukaemia. Blood Cancer J. 2021;11:136. https://doi.org/10.1038/s41408-021-00528-x. They compared spike-specific antibody responses to vaccination between 299 patients with CLL and healthy donors. Active treatment with BTK inhibitors was independently associated with a lack of antibody response. Titers of antibodies are significantly lower in CCL patients.

Publisher's Note Springer Nature remains neutral with regard to jurisdictional claims in published maps and institutional affiliations. 